\title{
Familial, isolated, complete right bundle-branch block
}

\author{
Eva Esscher, Lars-Ivar Hardell, and Magnus Michaëlsson \\ From the Department of Paediatrics, University Hospital, Uppsala, Sweden
}

\begin{abstract}
An electrocardiographic study of the families of two children with isolated complete right bundle-branch block is presented. Several cases of classical complete right bundle-branch block were disclosed (17/69 and 3/22 respectively) in three generations of the two families. Personal interviews and parish registers showed that the two families were related, being descendants 8 generations back from a glass-blower who had emigrated to Sweden in the eighteenth century.

It is concluded that complete right bundle-branch block can be an autosomal, genetic anomaly which is inherited dominantly but with reduced penetrance and/or expressivity.
\end{abstract}

Complete right bundle-branch block is seen rarely in children and young adults. In a study on 122043 apparently healthy male subjects aged from 16 to over 50 years, Hiss and Lamb (I962) found an incidence of right bundle-branch block of 1.8 per thousand. The rate increased from 0.5 in the agegroup I6 to 19 years to 2.9 per thousand in the agegroup 40 to 44 years. The increasing incidence in the older age-group suggests a progressive or an additional acquired lesion. Referring to the same study it has been suggested that right bundlebranch block may infrequently be a congenital anomaly (Ostrander, 1964). We have found only one published report of established congenital absence of the right branch of the bundle of His which occurred in a case with associated cardiovascular anomalies (Coakley, I95I).

To our knowledge 6 reports on the familial occurrence of complete right bundle-branch block have been published. Of the 6 papers, 4 describe familial clustering of atrioventricular conduction disturbances and right bundle-branch block (Combrink, Davis, and Snyman, 1962; Gazes et al., 1965; Simonsen and Madsen, 1970; Schaal et al., 1973). The two papers dealing with isolated right bundlebranch block with no other conduction disturbance (Mosetti, 1954; Trivella and Chella, 1960), report the finding in three adult brothers, and in a mother, her three sons, and a grandson. All were diagnosed in adulthood.

During a 20-year period we have seen 7 children with isolated right bundle-branch block among about 3000 cases with congenital heart disease. All seven have been catheterized and coexisting cardioReceived 31 October 1974. vascular malformations have been excluded. Two of the cases were known to have relatives with complete right bundle-branch block. These were a girl and her mother, and a boy and his father. The mother has been catheterized with normal findings. At the age of 29 years the father had bronchopneumonia. Because of the electrocardiographic findings at this time it was believed that he had a myocardial infarction.

In an attempt to study what appeared potentially to be a hereditary anomaly the following investigation was undertaken.

\section{Subjects, methods, and results}

Two families out of the seven were selected for examination of the electrocardiograms. The families lived in different parts of Sweden and there was no indication at that time that they were related to each other. In one family we knew that the mother of the proband was affected and in the second family no electrocardiographic abnormality was known. A physical examination was made of individuals with abnormal electrocardiographic findings.

The criteria for the diagnosis of complete right bundle-branch block were a duration of the QRS complex of $0.12 \mathrm{~s}$ or longer, as measured in the chest leads of a twelve-lead electrocardiographic tracing, and an $\mathrm{rSR}^{\prime}$ or $\mathrm{rR}^{\prime}$ pattern in leads VI to $\mathrm{V}_{2}$ together with a broad $S$ in leads $I$ and $V_{5}$ to V6. There is no general agreement about the upper limit for QRS duration in the different paediatric age groups. Therefore, children with the same change in the normal sequence of excitation as occurs in right bundle-branch block but with a duration of QRS 
less than $0.12 \mathrm{~s}$ were treated as a separate group. The plan was to study all living members of the families, that is parents and grandparents on both sides including their offspring. As the study progressed it was clear that a familial clustering was present and also on which side this clustering occurred, and therefore a few members on the 'non-affected' side were not examined. During the study it transpired that the two families came from the same small village in the northern part of Sweden. With the aid of interviews, of the parish registers, and of a man interested in the genealogy of immigrant glass-blowers, the families were found to be related, being descendants from a glassblower who emigrated to Sweden in the eighteenth century. As seen in the pedigree 17 out of 69 and 3 out of 22 individuals in generations VI, VII, and VIII of the two families were found to have right bundle-branch block. None of these had symptoms of heart disease. There were 9 children, 6 young adults, 16, 19, 20, 25, 32, and 42 years of age, and 5 adults over the age of 50 years. The QRS complex pattern was very similar in all cases with a rSR' complex in lead VI to V2, except in one boy who had an $\mathrm{rSr}^{\prime} \mathrm{R}^{\prime \prime}$ in these leads. There were no cases with atrioventricular conduction disturbances nor with left anterior hemiblock. Of the 9 children, 3 had a right bundle-branch block pattern but the QRS was less than $0.12 \mathrm{~s}$ in duration, and the other 6 children had a QRS duration of 0.I2 s or longer.

\section{Comment}

The study here presented supports the statement that right bundle-branch block may be congenital and may occur in the absence of significant cardiac disease. There was no case with atrioventricular block present among the members of the two

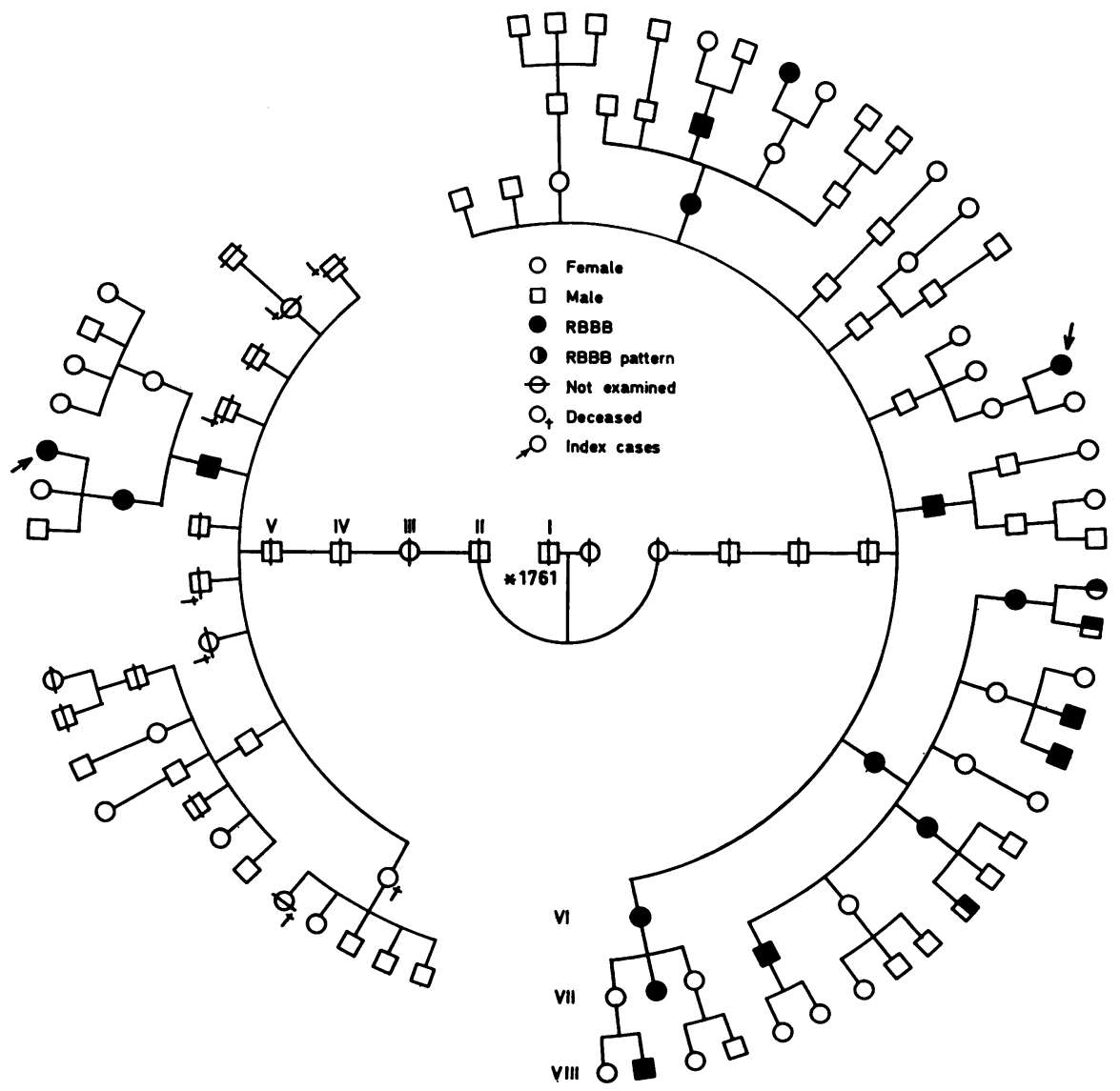

FI G. Pedigree of the two families with right bundle-branch block. In three cases with right bundlebranch block pattern the QRS was less than $0.12 \mathrm{~s}$. The arrows indicate the two index cases. 
families. The cases with right bundle-branch block did not show a left anterior hemiblock pattern. We, therefore, believe that the cases described by Combrink et al. (1962), Gazes et al. (1965), Simonsen and Madsen (1970), and Schaal et al. (1973) present other types of familial conduction disturbances. The cases described by Mosetti (1954) and by Trivella and Chella (1960) had right bundlebranch block with no other conduction anomaly; these two reports described adult cases only, which makes it more difficult to exclude the right bundlebranch block as being an acquired lesion. The considerable clustering and the incidence figures in the different generations in the families here studied seem to be convincing evidence that right bundlebranch block can be an autosomal genetic anomaly which is inherited dominantly with reduced expressivity and/or penetrance. There is no reason to believe that isolated right bundle-branch block would significantly affect physical capacity or life expectancy. We think that this optimistic view is supported by the present study where no other heart disease was disclosed in any case.

This study was supported by a grant from the Swedish National Association against Heart and Chest Diseases.

\section{References}

Coakley, J. B. (I95I). Congenital absence of the right branch of the bundle of His. British Heart fournal, 13, 148.

Combrink, J. M., Davis, W. H., and Snyman, H. W. (1962). Familial bundle branch block. American Heart fournal, 64, 397.

Gazes, P. C., Culler, R. M., Taber, E., and Kelly, T. E. (1965). Congenital familial cardiac conduction defects. Circulation, 32, 32.

Hiss, R. G., and Lamb, L. E. (1962). Electrocardiographic findings in 122,043 individuals. Circulation, 25, 947.

Mosetti, A. (1954). Blocco di branca familiare. Folia Cardiologica, 13, 527.

Ostrander, L. D. (1964). Bundle-branch block. An epidemiologic study. Circulation, 30, 872.

Schaal, S. F., Seidensticker, J., Goodman, R., and Wooley, C. F. (1973). Right bundle-branch block, left axis deviation, complete heart block, and early death. A heritable disorder of cardiac conduction. Annals of Internal Medicine, 79, 63 .

Simonsen, E. E., and Madsen, E. G. (1970). Four cases of right-sided bundle-branch block and one case of atrioventricular block in three generations of a family. British Heart fournal, 32, 501 .

Trivella, P., and Chella, S. (1960). Blocco di branca destra familiare e congenito. Minerva Cardioangiologica, 8, 186.

Requests for reprints to Dr. Magnus Michaëlsson, Department of Pediatrics, University Hospital, S-750 14 Uppsala, Sweden. 